\title{
A CRIANÇA COM PARALISIA CEREBRAL, O BRINQUEDO E A TECNOLOGIA ASSISTIVA: RELATO DE UM CASO
}

\section{Ivani Cristina Voos ${ }^{1}$}

Resumo: O presente trabalho objetiva investigar as relações estabelecidas por uma criança com paralisia cerebral e o brinquedo, bem como, os possíveis processos de desenvolvimento cognitivo envolvidos nesta relação. Durante o período de realização das atividades utilizou-se brinquedos adaptados e controlados com uso do acionador. Foi preciso apontar, com a participação da criança, qual o modelo de acionador mais indicado com as suas habilidades motoras. As atividades investigativas foram realizadas no Atendimento Educacional Especializado (AEE) de uma escola pública, com um estudante de 9 anos de idade com diagnóstico de paralisia cerebral. Os atendimentos foram vídeo-gravados e registrados no diário de bordo da professora de educação especial. Neste trabalho buscamos apresentar resultados parciais das atividades realizadas, visto a vigência dos atendimentos. Assim, diante da análise realizada, já é possível inferir que a oferta de brinquedos adaptados e o uso do acionador de pressão viabilizam melhor envolvimento e autonomia da criança com o ato de brincar e podem se tornar aliados no desenvolvimento de outras habilidades cognitivas, em destaque, a comunicação.

Palavras Chaves: Tecnologia Assistiva; Brinquedos Adaptados; Acionador; Atendimento Educacional Especializado.

\section{CHILDREN WITH CEREBRAL PALSY, PLAY, AND ASSISTIVE TECHNOLOGY: A CASE REPORT}

Abstract: This paper aims to investigate relationships and possible developmental processes of a child through play. During the period of the activities the need to offer adapted and device-controlled toys has been highlighted. Research activities have been carried out by Special Education Services faculty (Atendimento Educacional Especializado - AEE) at a public school, with a 9-year-old student diagnosed with cerebral palsy. The activities have been video-recorded. In this work we present partial results of the activities undertaken to the date. Thus, it is possible to infer that the supply of toys adapted for the use of the trigger use allow for involvement and autonomy of the child within the act of playing and can foster the development of functions such as communication.

Key words: Assistive Technology; Adapted Toys; Special Education Services 


\title{
1. INTRODUÇÃ̃O
}

\begin{abstract}
A brincadeira é a vida da criança e uma forma gostosa para ela movimentar-se e ser independente. Brincando, a criança desenvolve os sentidos, adquire habilidades para usar as mãos e o corpo, reconhece objetos e suas características, textura, forma, tamanho, cor e som. Brincando, a criança entra em contato com o ambiente, relaciona-se com o outro, desenvolve o físico, a mente, a auto-estima, a afetividade, tornase ativa e curiosa (SIAULYS, 2006, p.10).
\end{abstract}

As palavras da autora vêm ao encontro do foco das atividades realizadas neste estudo: possibilitar, através da brincadeira, que um estudante com diagnóstico de paralisia cerebral explore e conheça o ambiente em que vive, adquira habilidades corporais e comunicacionais que possibilitem a ampliação da participação social e educacional. $\mathrm{O}$ ato de brincar é de extrema importância para todas as crianças, mas para aquelas que têm limitações sensoriais, físicas ou intelectuais a brincadeira e o acesso a brinquedos acessíveis podem fazer toda a diferença no que tange a participação em atividades escolares, lúdicas e sociais.

Sendo assim, este trabalho objetiva investigar as relações estabelecidas por uma criança e o brinquedo, bem como, os possíveis processos de desenvolvimento cognitivo envolvidos nesta relação.

Baseado em princípios de igualdade e oportunidade, o presente estudo buscou e ainda busca desenvolver, no Atendimento Educacional Especializado (AEE), atividades que possibilitem o acesso a brinquedos adaptados com uso do acionador. Através desse acesso esperamos contribuir com o desenvolvimento de habilidades, destacando-se nesse momento, a comunicação. Expressar sentimentos, vontades, desejos é parte dos objetivos dos planejamentos que envolveram o uso do brinquedo e do acionador, além é claro, de ofertar um espaço de brincadeiras onde o estudante pudesse participar de forma autônoma, experienciando atividades ainda desconhecidas por ele.

Amparados em Finnie (1980), Oliveira et al (2009) explicam que brincando a criança aprende a conhecer a si, seu corpo em relação ao espaço e ao ambiente, bem como, pode explorar as diferentes propriedades dos objetos. Todas estas ações são, geralmente, dificultadas em crianças com algum tipo de deficiência, pois as mesmas nem sempre têm a possibilidade de explorar brinquedos diferentes, brincadeiras diversas e partilha-las com outras crianças, assim como se percebe dificuldades de acesso a brinquedos e experiências sensoriais variadas. Estes fatores podem refletir em "atraso" no ato de brincar. Como explicam os autores

(...) a criança com PC apresenta alterações em um ou mais desses componentes [fazendo referência aos cinco componentes do brincar descritos por Ferland (2006)], o que dificulta o acesso ao meio, aos brinquedos e os companheiros para as atividades lúdicas. Desse modo, o seu desempenho ocupacional para o brincar encontra-se deficitário, podendo, muitas vezes, não evidenciar a seqüência natural da atividade lúdica descrita nas diversas teorias e visível nas crianças não-deficientes, comprometendo seu desenvolvimento (OLIVEIRA et al, 2009, p. 174).

Outro aspecto que necessita destaque na questão de acesso ao brinquedo é o comercial. A maioria dos brinquedos disponibilizados na mídia não é acessível e de fácil manuseio para crianças com dificuldades motoras graves, sendo muitas vezes necessária a adaptação de brinquedos a fim de torná-los possíveis e manipuláveis com autonomia por esse público infantil.

O brincar pode possibilitar desenvolvimento de ações motoras, interações sociais e a ampliação das experiências sensoriais da criança envolvida através da exploração do corpo e do ambiente, assim como a comunicação estabelecida durante o ato de brincar pode ser potencializada no caso de crianças que não se expressam com o uso da oralidade. 


\section{REGISTROS, AVALIAÇÃO E REFLEXÃO: O CAMINHO PERCORRIDO}

O presente estudo é o resultado parcial de um trabalho que vem sendo desenvolvido no AEE em uma escola pública com um estudante, sexo masculino, de 9 anos de idade com diagnóstico de paralisia cerebral. O estudo teve início junto com as atividades realizadas no AEE no ano de 2014 e se estende até o presente momento. Os encontros com o estudante ocorrem semanalmente no contraturno escolar, na sala de recursos multifuncional.

No início do atendimento pode-se evidenciar que a criança em questão tinha pouco acesso a brinquedos que pudesse manusear de forma mais independente, fato este informado pelo familiar responsável na entrevista inicial realizada pela professora de educação especial que realiza o AEE. Outro aspecto relatado foram as expressões que o estudante usava para se comunicar com a família e que deveriam ser potencializados neste espaço, já que a família demonstrou que os mesmos eram muito sutis e de difícil percepção, e que muitas vezes não conseguiam compreender os desejos e vontades do estudante. Este relato e o contato com a criança permitiram perceber que a mesma demostrava pouco interesse pelos brinquedos apresentados, talvez por desconhecer a função deles.

Diante dos dados coletados a partir da entrevista e os primeiros contatos com a criança foi possível planejar as primeiras atividades. As mesmas foram planejadas pela professora de educação especial e visavam oferecer a oportunidade de brincar de forma autônoma, divertida, enfatizando-se o desenvolvimento das funções comunicativas. Tais atividades foram sendo replanejadas constantemente.

Nos primeiros atendimentos percebia-se baixa expressão comunicativa por parte do estudante. Mesmo conhecendo alguns dos sinais, por terem sido descritos anteriormente pelos familiares, esses, assim como suas expressões não eram muito perceptíveis. Aos poucos foi possível perceber que diferentes expressões faciais passaram a indicar, com maior significado, sinais como: felicidade, eu quero, eu não quero, não gostei e desconforto com relação aos sons produzidos pelos brinquedos. $\mathrm{O}$ caminho para refinar estes mecanismos de comunicação foi e ainda continua sendo árduo. Podemos perceber que o brinquedo controlado por acionador pode ter sido um importante recurso para esta caminhada. Os brinquedos adaptados assim como o recurso do acionador eram desconhecidos pelo estudante anteriormente ao início do AEE, por isso, para iniciar as atividades foi necessário seguir algumas etapas:

a) analisar, com ajuda do estudante, qual era o melhor modelo de acionador entre os que tínhamos acesso na sala de recurso multifuncional (pressão e tração), para as habilidades motoras apresentadas;

b) averiguar, com a ajuda do estudante, qual o melhor tamanho e cor, entre os disponíveis na sala de recursos multifuncional (grande e pequeno, nas cores azul, verde e vermelho), seria o mais indicado as suas necessidades e habilidades;

c) verificar, com ajuda do estudante, qual parte do corpo seria a mais adequada para o uso do acionador escolhido (com as mãos, pés, cabeça, joelhos);

d) examinar qual a postura (deitado, sentado, apoiado) seria a mais indicada para a sua estrutura corporal, bem como, qual recurso para a melhor adequação postural;

e) ensinar o estudante a perceber a ação/reação causada pelo uso do acionador ligado ao brinquedo;

f) possibilitar a exploração dos brinquedos disponíveis, a fim de explorar as características e propriedades dos mesmos. 
Cada uma das etapas descritas foram importantes, pois possibilitaram a participação do estudante na escolha dos recursos que melhor se adequavam as necessidades e habilidades apresentadas.

Foram necessários realizar alguns testes com o estudante a fim de verificar e apontar qual modelo de acionador (pressão ou tração) era o mais indicado, percebeu-se que diante as habilidades motoras demonstradas que a melhor escolha era o acionador de pressão. A cor e tamanho do botão também eram aspectos a serem avaliados. Notouse que o acionador tamanho grande na cor vermelha foi o que mais despendeu atenção por parte do estudante. Depois, colocamos o acionador escolhido em diferentes partes do corpo (mãos, pés, cabeça e joelho) e aos poucos foi se apresentando ao estudante como realizar o movimento e clicar no acionador, ficou mais evidente que o controle motor demonstrado com as mãos era superior as demais partes do corpo, evitando movimentos involuntários e desgaste físico.

Para finalizar esta etapa foi preciso averiguar qual a melhor postura, visto as atividades serem planejadas para que o estudante pudesse experienciar diferentes posições, em especial, daquelas usualmente utilizadas em casa e em sala de aula (sentado e deitado). Para isso, pediu-se o apoio e a avaliação de um fisioterapeuta. Assim como, confeccionou-se uma cadeira de chão baseada nas especificações dadas pelo profissional. $\mathrm{O}$ estudante, além do recurso da cadeira de chão, também teve acesso ao rodão, equipamento descrito no livro Brincar para Todos (SIAULYS, 2006, p. 56).

Por fim, era preciso ensinar ao estudante a perceber que o brincar dependeria de uma ação provocada no acionador e que isso resultaria em movimento no brinquedo. $\mathrm{O}$ processo não foi simples, precisa se manter em reavaliação. A busca por uma melhor adequação postural para brincar e o reconhecimento dos limites e as potencialidades dos brinquedos e do acionador precisam estar presentes. O caminho está em constante construção, já que a criança não teve nenhum acesso anterior a recursos com tais características. Explorar os brinquedos e conhecer as propriedades dos mesmos também foi muito importante para esta etapa.

A fim de acompanhar e registrar o estudo, as diferentes formas de expressão e maneiras de aprendizagem do estudante em relação ao uso do brinquedo e do acionador de pressão, ficou acordado em parceria com a família, vídeo-gravar os atendimentos. Segundo Carvalho e Garrido (1999), a prática do professor necessita ser refletida antes, durante e depois da ação. Para as autoras, as vídeo-gravações contribuem para as discussões acerca da prática desenvolvida pelo docente. As imagens falam por si e causam impacto, favorecendo a relação entre teoria e prática, assim permitindo ao docente refletir sobre as imagens e a teoria.

Além dos vídeos, todos os atendimentos, atividades e o desenvolvimento do estudante foram registrados num diário de bordo, denominado Diário de Bordo do Estudante. Ustra e Terrazzan (2000) explicam que:

(...) os Diários como instrumentos de acompanhamento e avaliação crítica-reflexiva da prática pedagógica. O trabalho com Diários permite aos professores reconstruírem as suas ações, explicitando-as e atribuindolhes razão e sentido. Através deles consegue-se identificar os elementos de significação e os sucessos, ou insucessos, que vão ocorrendo (USTRA e TERRAZZAN, 2000, p. 4).

Porlán e Martin (1997) explicam que os diários de bordo podem se tornar instrumentos importantes no desenvolvimento profissional do professor, visto estar imerso em uma atmosfera complexa, que muitas vezes aborda diversos problemas, aspecto este expressivo na área da educação especial. Corroborando com esta perspectiva acerca do uso do diário de bordo, Pacca (1994) aponta que o diário de bordo pode contribuir para que o professor atue de forma diferenciada, transformando a 
concepção de ensino, "uma oportunidade para dirigir as questões e dúvidas propostas para uma formulação objetiva, relativa à aprendizagem e motivação do aluno" (PACCA, 1994, p.61).

Ambos os instrumentos utilizados como dados de registro foram indispensáveis na realização desta análise, pois, possibilitaram permanente reflexão da professora de educação especial acerca do planejamento e das mediações realizadas com o estudante durante no período de a realização das atividades referidas nesse trabalho.

\section{BRINQUEDOS ADAPTADOS E O USO DO ACIONADOR: POSSIBILIDADES PARA UM ESTUDANTE COM PARALISIA CEREBRAL}

Todo o traballho que vem sendo desenvolvido, em especial, as etapas mencionadas acima, serviram de aprendizagem e reflexão para a professora de educação especial, especialmente no que se refere aos espaços que sinalizam para o desenvolvimento comunicacional e um estreitamento relacional cada vez mais expressivo do estudante com as brincadeiras, o brinquedo e o acionador.

Cada etapa foi relevante, em especial, destacamos a participação do estudante em todas elas. Acreditamos que, o processo de participação do usuário na escolha dos recursos de Tecnologia Assistiva, como os defendidos e divulgados pela Empowering Users Through Assistive Technology - EUSTAT (1999) possibilitam um envolvimento maior e uma significação para a pessoa com deficiência, sem posterior e rápido abandono do recurso. Segundo Galvão Filho (2009) "é fundamental a participação do usuário final como parceiro ativo na escolha das Tecnologias de Apoio que utiliza" (GALVÃO FILHO, 2009, p. 131).

Neste estudo foi utilizado um acionador de pressão, em tamanho grande e na cor vermelha. Pois, como descrito anteriormente foram as características do recurso que mais chamaram a atenção do estudante. Já que o usuário não se expressa oralmente foi necessário atentar para suas expressões corporais em relação ao recurso. $\mathrm{O}$ estudante apresenta quadro motor grave, necessitando mediação constante de um adulto para utilizar e segurar o acionador e o brinquedo. No início dos atendimentos, professora e aluno não tinham estabelecido relação comunicacional, porém, este quadro se modificou com o passar dos encontros. No presente momento da escrita deste trabalho, o estudante conseguia demonstrar, através de algumas expressões faciais sutis, por exemplo, quando estava com vontade ou não de brincar, quando queria pegar o brinquedo, também se comunicava através de choro e sorrisos.

Além das etapas de identificação do acionador e adequação postural mais apropriados, aconteceu aos poucos a introdução do brinquedo. Foram utilizadas histórias, pois no início o estudante demonstrou desconforto e susto quando o brinquedo era ligado, acreditamos que isso ocorreu por ele não ter percebido o efeito de ação/reação produzido pelo clique no acionador de pressão. Assim como, foram necessários vários encontros para que demonstrasse compreender a ação de apertar para ligar e soltar para desligar o brinquedo, ainda encontra-se no processo de aquisição da linguagem e ação corporal relacionada a este ato de brincar, sendo preciso mediação durante a brincadeira.

Os brinquedos e os acionadores disponíveis na sala de recursos multifuncionais foram adquiridos por meio de edital ${ }^{2}$ e foram comercializados por empresa especializada em recursos de Tecnologia Assistiva, portanto não foram customizados exclusivamente para este estudante. Entendemos a importância da customização, assim como, da identificação atenta para brinquedos acessíveis e adequados para o nível de desenvolvimento que são particulares a cada criança mesmo em diagnósticos similares. Porém, percebemos que os brinquedos e acionadores apresentados ao estudante estavam 
adequados às necessidades e às habilidades apresentadas, os mesmos estão demonstrados nas figuras 1 e 2 .

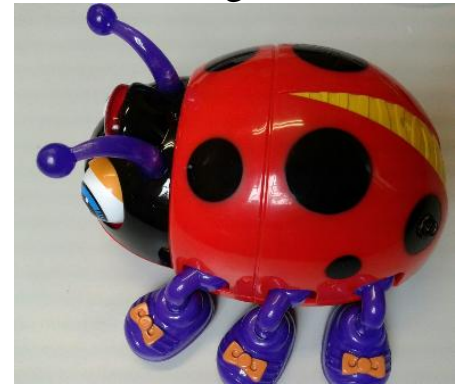

Figura 1: brinquedo adaptado com plug para acionador

Para a realização das atividades começávamos o atendimento contando a história infantil da Dona Joaninha cantora ou do Fusca falante, ambas criadas pela professora. Durante a realização das atividades expressava-se com sorrisos e movimentos corporais que indicavam alegria e satisfação. Após a história contada o acionador era oferecido ao estudante. Inicialmente, como já relatado, não compreendia a função do mesmo e quando realizava o clique, assustava-se com o som emitido pelos brinquedos. Este comportamento foi minimizado a partir do momento em que a ação de apertar o acionador começou a ganhar significado para o estudante. Durante a brincadeira, procuramos utilizar fragmentos da história contada, fazendo intervenções que objetivavam a comunicação, a atenção e a interpretação com relação a questões direcionadas, como: vamos colocar a Dona Joaninha para cantar? Vamos desligar a Dona Joaninha? Vamos parar o fusca? Também, foram ofertados momentos mais livres, onde o estudante pode apertar e desligar o mesmo conforme sua vontade.

Os brinquedos adaptados são um tipo de recurso de Tecnologia Assistiva de acordo com os conceitos encontrados na literatura, por exemplo, Bersch (2009), EUSTAT (1999), Galvão Filho (2009) entre outros. Sendo assim Oliveira et al (2009) explicam que,

[...] os recursos tecnológicos podem oferecer possibilidades lúdicas, permitindo à criança com PC a oportunidade de vivenciar experiências, minimizando os impedimentos e inserindo-as em ambientes que favoreçam o desenvolvimento, pois a partir do momento em que o indivíduo pode acessar, vivenciar e utilizar os recursos tecnológicos, as sequelas podem ser minimizadas (OLIVERA et al, 2009, p.176).

Podemos perceber aspectos relevantes neste tipo de recurso tecnológico, pois é através deles que muitas crianças com graves comprometimentos motores podem ter acesso a brincadeiras e estabelecem interações comunicativas antes não percebidas. No caso deste estudo, percebe-se que os brinquedos e o uso do acionador poderão ampliar o repertório comunicativo, as relações com o outro, a atenção e a concentração do estudante envolvido. Bem como, possibilitar a experiência de novas posturas e a relação com novos objetos até então pouco ou nada explorados. Este modelo de recurso de Tecnologia Assistiva, o brinquedo adaptado com uso de acionadores, possibilitam a exploração e o "domínio" do ambiente, já que muitas vezes os brinquedos são inadequados e inacessíveis, dificultando essas ações. Tais barreiras podem levar ao desconhecimento da função dos brinquedos e a inadequada relação da criança com o brinquedo.

O estudante, anterior a essa experiência, possivelmente, enfrentava dificuldades e barreiras nas relações com o brinquedo, sendo restrito seu repertório de brincadeiras e o acesso a recursos, fato este que explica alguns comportamentos apresentados. Porém, é possível averiguar através dos registros e do envolvimento do estudante com as 
atividades que o desenvolvimento cognitivo apresentado e as atitudes em relação ao brincar foram modificadas e estão em constante aprimoramento.

\section{CONSIDERAÇÕES FINAIS}

A partir da revisão de literatura realizada e do presente estudo foi possível evidenciar a importância do brincar para todas as crianças, em especial, para aquelas que não podem realizar está função social de forma independente e autônoma.

Os resultados preliminares obtidos a partir da análise realizada nos permitiu inferir que o acesso ao brinquedo adaptado com uso do acionador possibilitou ao estudante momentos de aprendizagem, bem como, o desenvolvimento de funções cognitivas anteriormente não percebidas ou não demonstradas, em especial, a comunicação. Sabemos que ainda são pequenos e sutis os resultados alcançados e que muito temos a caminhar, pois entendemos que o processo de desenvolvimento não é linear.

A cada encontro realizado o estudante apresentava comportamentos diferentes e a vontade e o desejo de participação nas atividades alternam-se. Mesmo assim, podemos indicar, com base nos registros realizados, que os momentos positivos em que expressou desejo em participar sobressaíram-se as negativas. Fato esse que indica estarmos no caminho mais acertado, pois acima de qualquer aspecto que possa se fazer presente neste estudo, o respeito às individualidades e particularidades do estudante é o mais relevante.

Embora tenhamos consciência de que não há certo ou errado, nem há prescrição de atividades para o uso de brinquedos adaptados e o uso de acionadores, as expressões e o envolvimento do estudante com as atividades propostas nos dão indicativos que o brinquedo adaptado pode ser um importante recurso de Tecnologia Assistiva no desenvolvimento cognitivo de crianças com paralisia cerebral. Faz-se importante ressaltar que as indicações aqui apresentadas e os trajetos seguidos neste estudo foram sendo modificados de acordo com o perfil do estudante e que talvez não sejam os mais adequados para outras crianças com este diagnóstico, visto que há singularidades (motoras, intelectuais e sensoriais) nas pessoas com paralisia cerebral. Seguir as etapas apresentadas, respeitar as peculiaridades individuais e valorizar a participação do indivíduo no processo de organização das atividades pode e muito favorecer a aprendizagem e o desenvolvimento cognitivo, bem como significar o uso dos recursos de Tecnologia Assistiva escolhidos.

É preciso ainda ressaltar que ao longo do texto expusemos a ideia de brincar de forma autônoma, não almejamos uma autonomia utópica e sim que este estudante possa experienciar um envolvimento com o brinquedo e a brincadeira antes desconhecido. Que tais atitudes sejam baseadas em desejos e escolhas próprias, mesmo que minimamente expressado visto o quadro sensório-motor apresentado.

Esse estudo aponta para a relevância de desenvolvermos e oportunizarmos mais espaços lúdicos que envolvam a exploração de diferentes brinquedos, brincadeiras, formas de linguagem e adequações posturais para a criança com paralisia cerebral, tanto no espaço educacional como doméstico. Assim como, apontam para a reflexão docente diante a prática pedagógica realizada no AEE, indicando que é preciso ir e vir quantas forem às vezes necessárias, valorizando a atuação da pessoa com deficiência no ato de brincar, mesmo que mediado por um adulto.

Muitos passos precisam ser dados no caminho traçado para o estudante, porém muitos já foram dados e este trabalho é apenas um pequeno relato frente à imensidão que tais encontros representaram na vida de ambos os envolvidos - professora e estudante. 


\begin{abstract}
NOTAS
1 Doutoranda do Programa de Pós Graduação em Educação Científica e Tecnológica da Universidade Federal de Santa Catarina.

2 Os brinquedos foram adquiridos através do Programa LIFE-UFSC e do Edital CAPES 067/2013 Auxpe 3225/2013. O Programa LIFE é "Um Programa de Apoio aos Laboratórios Interdisciplinares de Formação de Educadores (Life) lançado no segundo semestre de 2012, para apoiar a criação e estruturação de ambientes plurais e interdisciplinares, que proporcionem aos estudantes dos cursos de licenciatura, formação baseada na articulação entre conhecimentos, práticas e no uso das novas linguagens e tecnologias educacionais." A pesquisadora é colaboradora do Programa e contribui com a formação de docentes e de estudantes dos cursos de licenciaturas, que atuam como estagiários nas diferentes áreas de ensino na instituição.
\end{abstract}

\title{
5. REFERÊNCIAS BIBLIOGRÁFICAS
}

BERSCH, Rita de Cássia Reckziegel. Design de um serviço de Tecnologia Assistiva em escolas públicas. Porto Alegre: UFRGS, 2009. 231 p. Dissertação de Mestrado.

BRASIL. Decreto número 5296, de 2 de dezembro de 2004.

BRASIL. Portaria número 142, de 16 de novembro de 2006.

CARVALHO, Anna Maria Pessoa e GARRIDO, Elsa. Reflexão sobre a prática e qualificação da formação inicial docente. Cadernos de Pesquisa, n. 107, p.149 - 168, julho de 1999.

EUSTAT. Educação em tecnologias de apoio para utilizadores finais: linhas de orientação para formadores. $1999 . \quad$ [Disponível em: http://www.siva.it/research/eustat/eustgupt.html, acessada em: 9 de março de 2013].

FERLAND, F. O Modelo Lúdico: O Brincar, a Criança com Deficiência Física e a Terapia Ocupacional. 2006. 3. ed. São Paulo: Roca.

GALVÃO FILHO, Teófilo Alves. Tecnologia assistiva para uma escola inclusiva [recurso eletrônico]: apropriação, demanda e perspectivas, no estado da Bahia. Bahia: UFBA, 2009. 346 p. Tese de doutorado.

OLIVEIRA, Ana Irene Alves de; PAIXÃO, Glenda M. da e CAVALCANTE, Marcos Vinícius C. Brinquedos adaptados para crianças com paralisia cerebral. Revista do Nufen, ano 1, v.1, p. 171-186, 2009.

OLIVEIRA, Ana Irene Alves de; PAIXÃO, Glenda M. da e CAVALCANTE, Marcos Vinícius C. Atividade lúdica adaptada para a criança com déficit no desempenho motor. In: Congresso Brasileiro Multidisciplinar de Educação Especial e VII Encontro da Associação Brasileira de pesquisadores em Educação Especial, 6, 2011, Londrina. Anais: Londrina: Associação Brasileira de pesquisadores em Educação Especial.

PACCA, J.L.A. A Atualização do Professor de Física do Segundo Grau-uma proposta. Tese de Livre Docência. São Paulo. FEUSP, 1994.

PORLÁN, Rafael; MARTIN, José. El diario del profesor: un recurso para la investigación en el aula, Sevilla. Díada, 1997.

SIAULYS, Mara O. C. Brincar para Todos. Ministério da Educação e Cultura. 2006.

USTRA, Sandro Rogério Vargas e TERRAZZAN, Eduardo A. Diários da prática pedagógica na educação continuada de professores de ciências. In: III Seminário Pesquisa e, Educação Região Sul - AnpedSul, 3, 2000, Porto Alegre. Anais. Porto Alegre: Anped. 
VYGOTSKI, L.S. Obras Escogidas V Fundamentos de Defectologia. 1983. Editora Pedagógica, Moscú. De La presente edición.

VYGOTSKI, L.S. A formação social da mente - o desenvolvimento dos processos psicológicos superiores. São Paulo. Martins, 1984.

VYGOTSKI, L.S. Pensamento e Linguagem. São Paulo. Martins, 1986. 